\title{
Decision Support System for Optimally Managing Water Resources to Meet Multiple Objectives in the Savannah River Basin
}

\author{
Edwin A. Roehl, Jr. ${ }^{1}$ and Paul A. Conrads ${ }^{2}$
}

\begin{abstract}
AUTHORS: ' $C$ Chief Technical Officer, Advanced Data Mining Intl, 3620 Pelham Rd., PMB 351, Greenville, SC 29615; 864201-8679; ed.roeh1@advdmi.com; ${ }^{2}$ Research Hydrologist, U.S. Geological Survey, South Atlantic Water Science Center, 720 Gracern Rd, Suite 129, Columbia, SC 29210; 803-750-6140; pconrads@usgs.gov.
\end{abstract}

\begin{abstract}
Managers of large river basins face conflicting demands for water resources such as wildlife habitat, water supply, wastewater assimilative capacity, flood control, hydroelectricity, and recreation. The Savannah River Basin, for example, has experienced three major droughts since 2000 that resulted in record low water levels in its reservoirs, impacting dependent economies for years. The Savannah River estuary contains two municipal water intakes and the ecologically sensitive freshwater tidal marshes of the Savannah National Wildlife Refuge. The Port of Savannah is the fourth busiest in the United States, and modifications to the harbor to expand ship traffic since the 1970s have caused saltwater to migrate upstream, reducing the freshwater marsh's acreage more than 50 percent. A planned deepening of the harbor includes flow-alteration features to minimize further migration of salinity, whose effectiveness will only be known after all construction is completed.

One of the challenges of large basin management is the optimization of water use through ongoing regional economic development, droughts, and climate change. This paper describes a model of the Savannah River Basin designed to continuously optimize regulated flow to meet prioritized objectives set by resource managers and stakeholders. The model was developed from historical data using machine learning, making it more accurate and adaptable to changing conditions than traditional models. The model is coupled to an optimization routine that computes the daily flow needed to most efficiently meet the water-resource management objectives. The model and optimization routine are packaged in a decision support system that makes it easy for managers and stakeholders to use. Simulation results show that flow can be regulated to substantially reduce salinity intrusions in the Savannah National Wildlife Refuge, while conserving more water in the reservoirs. A method for using the model to assess the effectiveness of the flow-alteration features after the deepening also is demonstrated.
\end{abstract}

\section{INTRODUCTION}

The Savannah River Basin (Basin; Figure 1a) is a prototypical large basin whose water-resource managers face conflicting demands, such as wildlife habitat, water supply, wastewater assimilative capacity, flood control, hydroelectricity, and recreation. In the upper Basin, the U.S. Army Corps of Engineers (USACE) controls three large reservoirs - Lake Hartwell, Richard B. Russell Lake (Lake Russell), and J. Strom Thurmond Lake (Lake Thurmond). Lake Russell has comparatively little storage, leaving Lakes Hartwell and Thurmond to provide most of the regulated flow to the coast. Since 2000 the upper Basin has experienced three major droughts, resulting in record and near-record low reservoir water-level elevations that impacted dependent economies by reducing tourism and real estate values (Allen et al., 2010; USACE, 2014).

The Savannah River estuary (estuary; Figure 1b) contains two municipal water intakes and the ecologically sensitive freshwater tidal marshes of the Savannah National Wildlife Refuge (Refuge). The interaction of regulated streamflow, tides, and weather produces salinity intrusions more than 25 miles upstream at U.S. Geological Survey (USGS) gage 02198840 . The gage is located where the river intersects Interstate 95 (I95), and near the City of Savannah's municipal freshwater intake on Abercorn Creek.

The Port of Savannah is the fourth busiest in the United States, and modifications to the harbor to enable more ship traffic have caused saltwater to migrate upstream, reducing the Refuge's freshwater marsh's acreage more than 50 percent since the 1970s (Conrads et al., 2006). A currently planned deepening of the harbor includes flow-alteration features to minimize further salinity migration; however, the estuary's complex hydrology and the extensive scope of all the construction make the final outcome uncertain. For example, a tide gate installed during the 1970s in the estuary's Back River to reduce shoaling unintentionally increased salinities and decreased dissolved-oxygen levels in the habitat of a large striped bass population. A consequent 


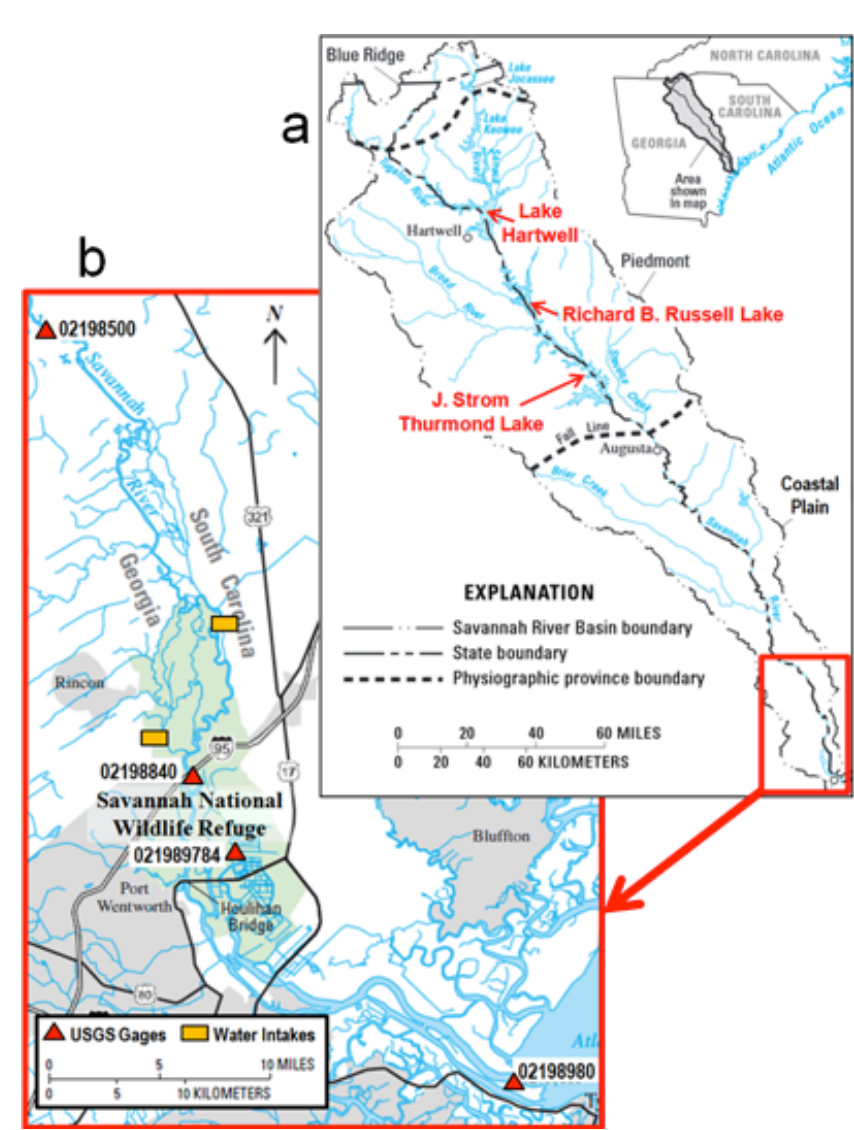

Figure 1. Maps showing the a) Savannah River Basin and b) lower Savannah River.

97\% decrease in striped bass abundance led to the tide gate being decommissioned in 1991(Reinert, 2004).

Managing the water resources of the Basin in an optimal way will require a tool that can determine on an ongoing basis how water should be allocated for multiple purposes, such as regional economic development, drought protection, and reducing salt-water intrusion and sea-level rise impacts. The general solution is to save water for future use by reducing regulated flows to the minimum volume needed to meet objectives prioritized by resource managers and stakeholders. Meeting the increasing and often conflicting usage demands in a constantly changing hydrologic system like the Savannah River Basin is an ongoing, multi-objective optimization problem. This paper describes the development of a decision support system (DSS) using artificial neural network (ANN) models that continuously optimize water levels in Lakes Hartwell and Thurmond while reducing salinity in the Refuge and near coastal municipal intakes.

\section{PROJECT DESCRIPTION}

This project built upon two previous studies. The first developed an empirical hydrodynamic and water-quality model of the lower Savannah River to estimate the impacts of the planned harbor deepening on the Refuge (Conrads et al., 2006). The model was developed from historical data using ANNs (Jensen, 1995), a form of machine learning. The model was packaged in a spreadsheet-based DSS (Roehl et al., 2006), making it easy for managers and stakeholders to use. It was named the Model-to-Marsh DSS (M2MDSS) because it connected two other models together: a 3-D finite-difference hydrodynamic model of the estuarine rivers and shipping channel (Tetra Tech, 2005), and a "plant succession model" of the sensitivity of the Refuge's marsh plant communities to salinity (Welch and Kitchens, 2006).

A second study modified the M2M-DSS, renamed M2M2-DSS, to estimate how sea-level rise and climate change would affect the magnitudes, frequencies, and durations of salinity intrusion events in the lower Savannah River (Conrads et al., 2013). This project developed a third version of the M2M-DSS, named M2M3-DSS, to study how the water resources of the upstream reservoirs could be managed differently to better protect the Refuge from salinity migration and to conserve water.

Figure $2 \mathrm{a}$ shows the normalized measured $(\mathrm{m})$ waterlevel elevations (ELV) of Lakes Hartwell and Thurmond in feet (ft), labeled ELV.Hart.m and ELV.Thur.m, for the February 10, 2007, to January 8, 2012, study period. All the time series presented herein use a daily time step. Normalization was performed by subtracting full pond elevations from the measured elevations. Lakes Hartwell and Thurmond reached their lowest and second lowest elevations, respectively, during the winter of 2008.

Figure $2 \mathrm{~b}$ shows two flows $(\mathrm{Q})$, the measured regulated flow from Lake Thurmond (Q.Thur.m), and the streamflow at USGS gage 02198500 near the town of Clyo (Q.Clyo.m). The study period includes the climatic extremes of two severe droughts and an El Niño episode. The Lake Thurmond flow contributes most of the flow at Clyo, with additional flow due to rainfall runoff and groundwater discharge between the gaging sites. During the droughts, Q.Thur.m was held nearly constant at the regulatory minimum flow deemed necessary to protect downstream water intakes and the Refuge. Figure $2 \mathrm{c}$ shows the measured maximum $(\max )$ and minimum (min) water levels (WL) in Savannah Harbor (WL.max.m and WL.min.m) recorded at USGS gage 02198980. The major factors causing the water-level variability are tides, weather, and streamflow.

Figure $2 \mathrm{~d}$ shows the measured maximum specific conductance in the Refuge and at 195 (SC.Rfg.max.m and SC.I95.max.m, respectively) recorded at USGS gages 021989784 and 02198840. Specific conductance (SC) is the field measurement used to compute salinity. The spikes indicate intrusion events that occur during spring tides of the new moon when tidal ranges are greatest. Tides having a low range are called neap tides. Annual specific conductance cycles coincide with those of the water levels in Figure 2c. Specific conductance is also modulated by weather and streamflow, which vary the magnitudes and durations of intrusion events. 

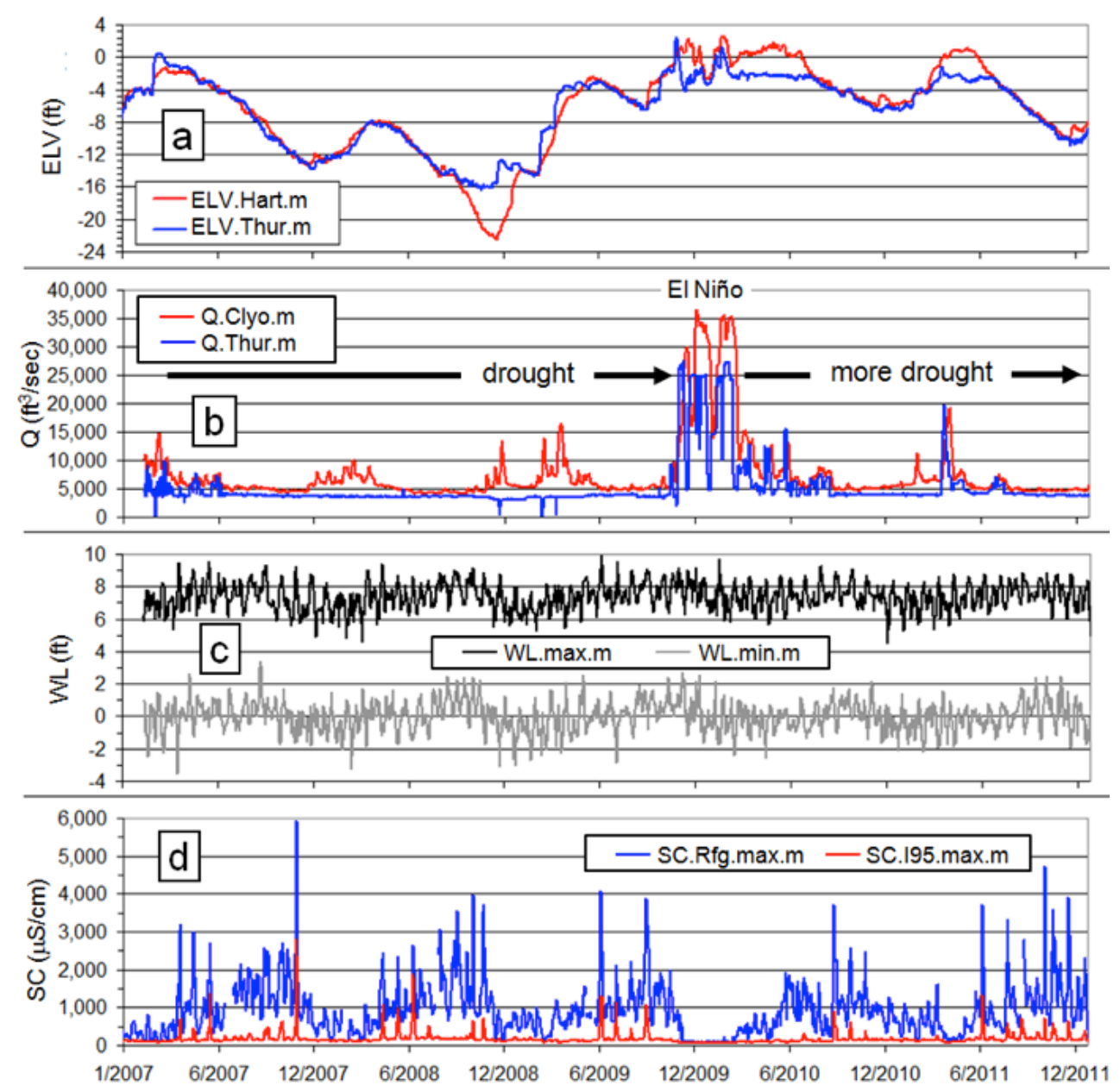

Figure 2. Measured data used in the study: a) normalized water elevations (ELV) for Lakes Hartwell and Thurmond (ELV.Hart.m, ELV.Thur.m), b) flow from Lake Thurmond (Q.Thur.m) and streamflow at Clyo (Q.Clyo.m), c) maximum and minimum Savannah Harbor water levels (WL.max.m, WL.min.m, respectively), and d) maximum specific conductance in the Refuge (SC.Rfg.max.m) and at 195 (SC.I95.max.m).

\section{METHODS}

ANNs synthesize nonlinear functions to fit multivariate calibration data rather than use predefined functions like mechanistic and statistical models. ANNs can adapt to changing conditions by updating the calibration data, and have been applied to a number of hydrology problems.

ANN models have been used to predict unmeasured riverine flows at locations between USGS gauging sites (Karunanithi et al. 1994), model flow conditions that lead to interfacial mixing in estuaries with vertical salinity and temperature stratification (Grubert, 1995), forecast salinity at an estuary site (Maier and Dandy, 1997), and forecast river stages in real-time (Thirumalaiah and Deo, 1998). Conrads and Roehl (1999) and Conrads and Greenfield (2010) found that ANN models of the Cooper and Savannah River estuaries had significantly lower prediction errors than mechanistic models of the same systems and executed much faster.

Fast execution allows a model to be coupled to an optimization routine that systematically tests and finds values for the model's controllable inputs, so that the model generates the output needed to meet one or more objectives. Dowla and Rogers (1995) combined an ANN-based groundwater model with optimization to evaluate millions of possible well patterns for remediating a contaminated site, and credited the approach with a potential $\$ 100$ million savings in remediation costs. A DSS that incorporated dissolved-oxygen concentration models with optimization was used to estimate the total maximum daily loads (TMDL) for biochemical oxygen demand and ammonia for three wastewater treatment plants on the Beaufort River (Conrads et al., 2003). To facilitate the relicensing of hydropower facilities on the Yadkin River by the Federal Energy Regulatory Commission, a DSS was developed that incorporated salinity models of the Waccamaw River and the Atlantic Intracoastal Waterway with optimization. The DSS was used to estimate the minimum flows required to prevent salinity inundation of municipal freshwater intakes in the Grand Strand (Conrads and Roehl, 2007).

The M2M3-DSS's optimization routine computes the predicted (p) flows at Clyo (Q.Clyo.p) needed to meet setpoints using ANN model predictions of average (avg) 
and maximum specific conductance in the Refuge and at 195 (SC.Rfg.avg.p, SC.Rfg.max.p, SC.I95.avg.p, and SC.I95.max.p, respectively). The predicted flows from Lake Thurmond (Q.Thur.p) are calculated by subtracting the difference between the measured Clyo and Lake Thurmond flows from Q.Clyo.p. Lake elevation setpoints are input to the M2M3-DSS as hydrographs and are used to calculate the flows needed from each lake to meet Q.Thur.p. The userspecified specific conductance setpoints have priority over the elevation setpoints. Flows from Lakes Hartwell and Thurmond are balanced so that they are kept equidistant from their elevation setpoints. This closely matches the current management practice in which "rule curves" are used to set outflows according to the month of the year and the current elevations.

To develop the ANNs, historical USGS data were randomly partitioned into training and testing datasets. The measured Clyo flow and harbor maximum and minimum water-level signals were decomposed into different frequency components that represent variability on daily, weekly, monthly, and seasonal time scales. During training, an ANN effectively selects the frequency components that provide the best fit. Figure 3 shows the measured and predicted maximum specific conductance in the Refuge and at 195. The Refuge model's coefficients of determination $\left(\mathrm{R}^{2}\right)$ for the training and testing datasets were 0.76 and 0.71 , respectively. The 195 model's $\mathrm{R}^{2}$ for the training and testing datasets were 0.67 and 0.72 , respectively. More details about developing ANN models of estuary specific conductance are given in Conrads et al. (2013).

\section{RESULTS}

Two simulations were performed to evaluate different resource management issues. Conrads and Greenfield (2010) had used the M2M-DSS to estimate the effect of a timed streamflow pulse on a large intrusion event recorded at 195. Scenario 1 (s1) extended this idea to determine if modulating water releases according to changing conditions could reduce salinity in the Refuge and upstream at I95, while also conserving water in the lakes. Scenario 2 (s2) simulated a substantial change to the harbor to demonstrate how the M2M3-DSS could be used to detect changes in salinity behavior caused by alterations to the harbor.

Scenario 1 used five setpoints representing different optimization objectives. To simulate protecting the City of Savannah's municipal freshwater intake, the setpoint for the predicted maximum specific conductance at I95 (s1.SC.I95. max.p) was $1,000 \mu \mathrm{S} / \mathrm{cm}$, which equates to a commonly used upper limit for freshwater (freshwater limit) of 0.5 practical salinity units. The setpoint for the predicted maximum specific conductance in the Refuge (s1.SC.Rfg.max.p) was $2,000 \mu \mathrm{S} / \mathrm{cm}$, a limit that was regularly exceeded in the measured data (Figure 2d). Note that frequently the reservoir outflows would need to be higher than the historical outflows to meet these two setpoints. To compensate for the higher outflows, a third setpoint for the predicted average specific conductance in the Refuge (s1.SC.Rfg.avg.p) was $650 \mu \mathrm{S} /$ $\mathrm{cm}$, which was higher than the $561 \mu \mathrm{S} / \mathrm{cm}$ measured average for the study period, but was still well below the freshwater limit. Two setpoints for predicted elevations of Lakes Hartwell and Thurmond (s1.ELV.Hart.p and s1.ELV.Thur.p) were full pond $+2.0 \mathrm{ft}$; these elevations have commonly been exceeded.

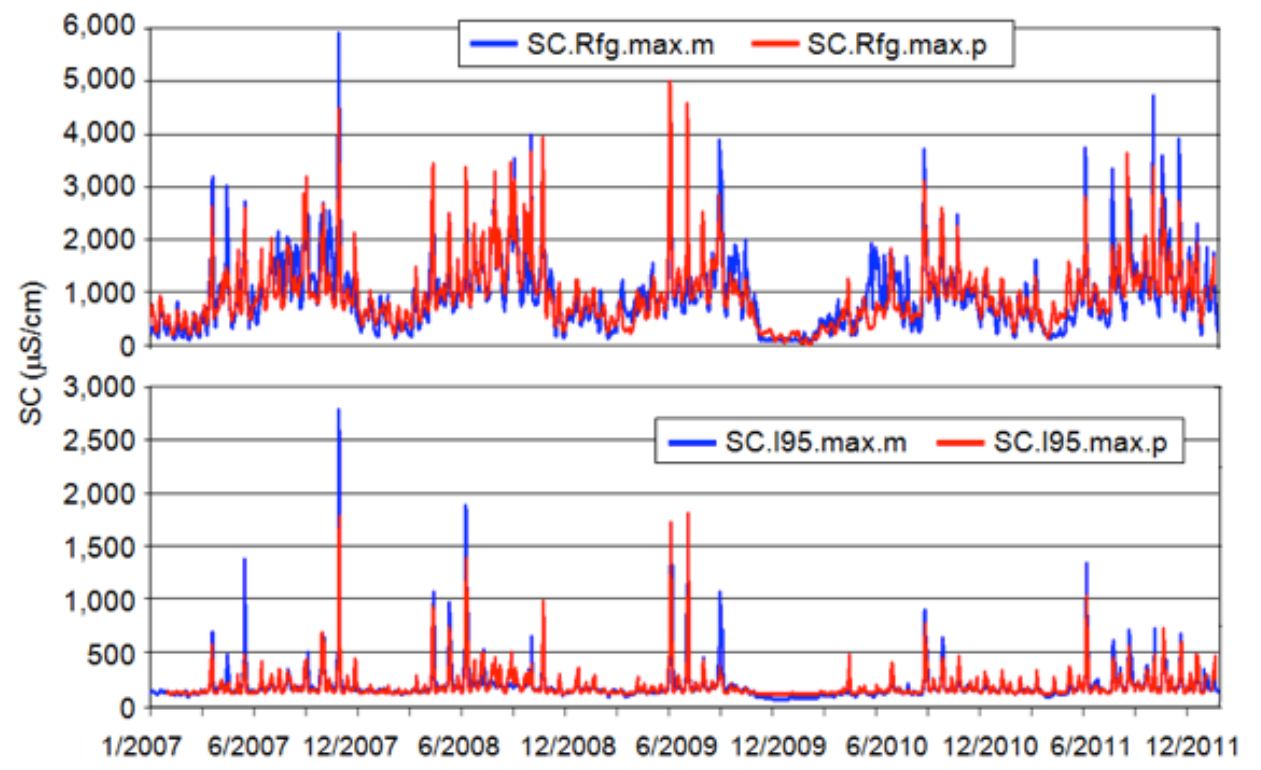

Figure 3. Measured (m) and predicted (p) maximum specific conductance (SC) in the Refuge and at I95 (SC.Rfg. max.m, SC.Rfg.max.p, SC.I95.max.m, SC.I95.max.p). 

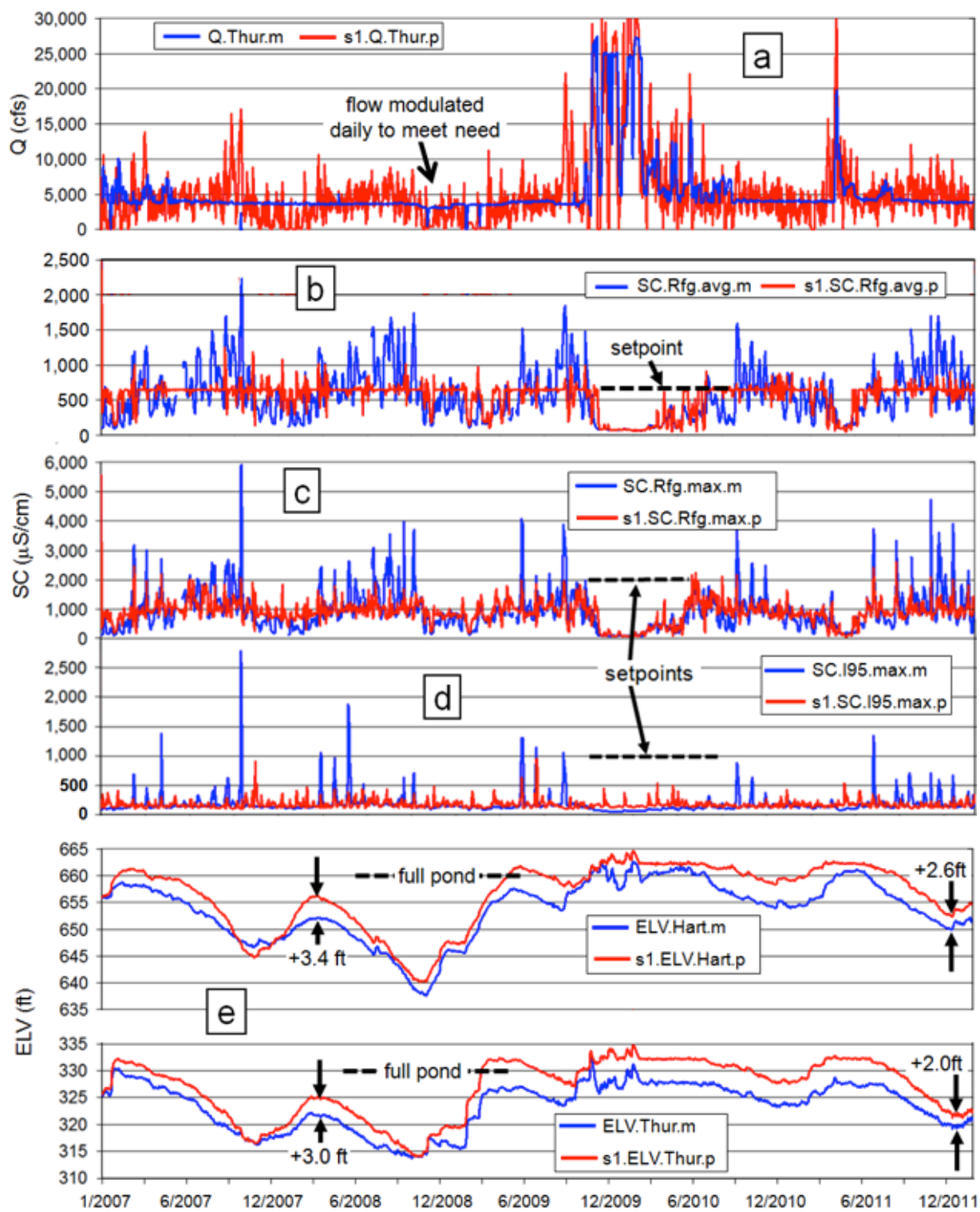

Figure 4. Measured (m) and Scenario 1 (s1) simulated data of a) Lake Thurmond outflows (Q.Thur.m, s1.Q.Thur.p), b) Refuge average specific conductance (SC.Rfg.avg.m, s1.SC.Rfg.avg.p), c) Refuge maximum specific conductance (SC.Rfg.max.m, s1.SC.Rfg.max.p), d) maximum specific conductance at I95 (SC.I95.max.m, s1.SC.I95.max.p), and e) Lakes Hartwell and Thurmond elevations (ELV.Hart.m, s1.ELV.Hart.p, ELV.Thur.m, s1.ELV.Thur.p).

The Scenario 1 results showed that predicted flow from Lake Thurmond (s1.Q.Thur.p) was much more variable than the measured flow (Q.Thur.m) (Figure 4a). Apart from the El Niño episode, the s1.Q.Thur.p trends with the largely periodic, and therefore predictable, water-level signals shown in Figure 2c. The predicted flows eliminated most of the spikes in the Refuge's measured average specific conductance SC.Rfg.avg.m, but also allowed the predicted average specific conductance s1.SC.Rfg.avg.p to rise to the $650 \mu \mathrm{S} / \mathrm{cm}$ setpoint when SC.Rfg.avg.m was lower than the setpoint, as seen during December 2007 (Figure 4b). The few predicted values above the setpoint resulted from an optimization constraint that limited daily flow changes in order to dampen flow variability. The number of days when the freshwater limit was exceeded was predicted to decrease from 230 to $34(-85 \%)$.
Figure $4 \mathrm{c}$ compares the measured and predicted maximum specific conductance in the Refuge, SC.Rfg. max.m and s1.SC.Rfg.max.p. The number of days when the Refuge's maximum specific conductance exceeded the $2,000 \mu \mathrm{S} / \mathrm{cm}$ setpoint was predicted to decrease from 126 to $10(-92 \%)$. Figure $4 d$ compares the measured and predicted maximum specific conductance at I95, SC.I95. max.m and s1.SC.I95.max.p. The number of days when the maximum specific conductance at I95 exceeded the freshwater limit was predicted to decrease from 16 to 0 $(-100 \%)$. Figure $4 \mathrm{e}$ shows that the predicted elevations of Lakes Hartwell and Thurmond, s1.ELV.Hart.p and s1.ELV.Thur.p, were generally higher than the measured elevations, with average increases of 2.7 and $3.4 \mathrm{ft}$ for the study period, respectively. 
Scenario 2 demonstrated that a system similar to the M2M3-DSS could be used to promptly identify changes after the deepening occurs. The idea was that an accurate model of the estuary's pre-deepening behavior can be used as a reference for quantifying the effects of later changes. The planned deepening will increase the depth of the navigation channel by $5.0 \mathrm{ft}$. To create a surrogate, post-deepening dataset, the effect of a $2.0-\mathrm{ft}$ sea-level rise on the Refuge's average specific conductance was simulated. The surrogate dataset, s2.SC.post, had a study-period average of $902 \mu \mathrm{S} / \mathrm{cm}$ versus $562 \mu \mathrm{S} / \mathrm{cm}$ for the measured data, an increase of $61 \%$ (Figure 5a). The number of days exceeding the freshwater limit increased $220 \%$. The model's representation of the Refuge's pre-deepening behavior consisted of predictions made using only measured input data, s2.SC.pre. The 95th percentile prediction error $(\varepsilon)$ was $348 \mu \mathrm{S} / \mathrm{cm}$.

Figure 5b shows s2.SC.pre $+\varepsilon$ and s2.SC.post with Running\%, the running percentage of days from the start of the study period when s2.SC.post exceeded s2.SC.pre $+\varepsilon$. Initially, Running\% generally followed the annual specific conductance trend, and then stabilized to a range between $40 \%$ and $50 \%$. The higher s2.SC.post values shown in Figure 5 a became apparent in the Running\% within the first 3 months of the study period. Discriminating the higher values was made possible by the accuracy of the model's representation of the pre-deepening system behavior. Quickly detecting and correcting adverse consequences of actions is necessary to manage the resource most effectively.

\section{DISCUSSION}

Scenario 1 indicated that episodic high salinity at multiple locations can be controlled by parsimonious reservoir releases that conserve water. The values chosen for the three specific conductance setpoints were somewhat arbitrary, with the freshwater limit being used as an example standard for two of them. However, all three setpoint values aimed to significantly reduce the predicted salinity below the measured salinity (Figures $4 b, 4 c, 4 d$ ), requiring reservoir outflows that were frequently much higher than the measured outflows (Figure 4a). The two chosen elevation setpoint values were consistent with observed USACE operating practices. In an operational M2M3-DSS, setpoint values could be adjusted when warranted by changing Basin conditions or new information. Additional setpoints and constraints could be added to represent other concerns, however, too many would limit operating flexibility.

Determining the dollar value of the water saved requires further study; however, the 2.7 and $3.4 \mathrm{ft}$ average elevation increases in Lakes Hartwell and Thurmond equate to 151,200 and 241,400 acre-ft for deferred power generation, respectively. Given that droughts vary in severity and duration, and can appear in rapid succession (Figure 2b), slower elevation decreases would increase the probability that dependent economies would emerge from droughts less affected.

Scenario 2 showed how a model that is accurately calibrated for one set of conditions can be a tool for quickly detecting and quantifying adverse differences caused by a new set of conditions. The impetus for employing such a tool for the deepening emanates from: uncertainty about the net

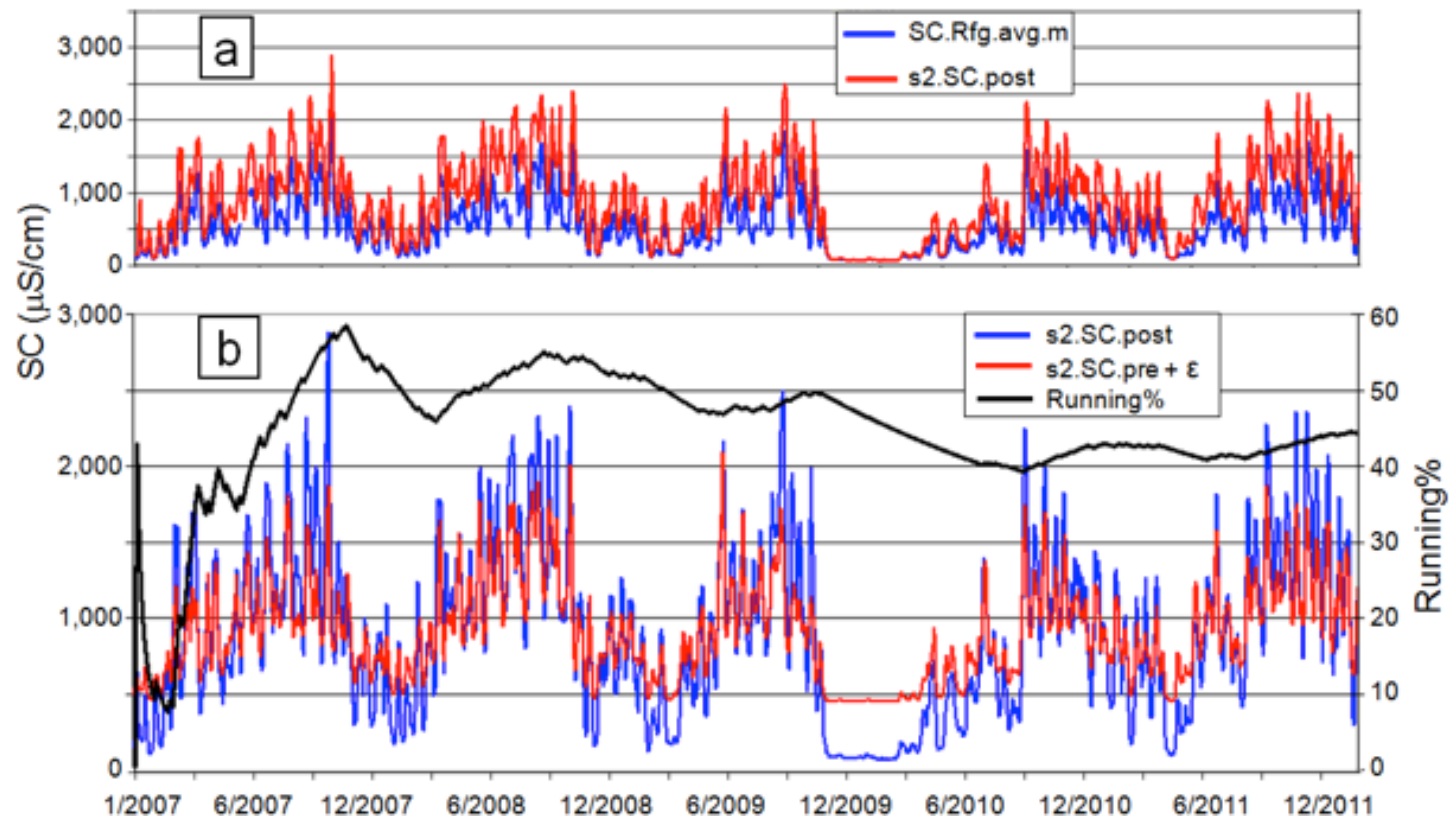

Figure 5. Scenario 2 (s2) results for the Refuge: a) measured and surrogate post-deepening average specific conductance (SC. Rfg.avg.m, s2.SC.post), and b) s2.SC.post and simulated pre-deepening average specific conductance $+95^{\text {th }}$ percentile model prediction error $\varepsilon=348 \mu \mathrm{S} / \mathrm{cm}$ (s2.SC.pre $+\varepsilon)$, and running percent of days when s2.SC.post exceeded s2.SC.pre $+\varepsilon($ Running $\%)$. 


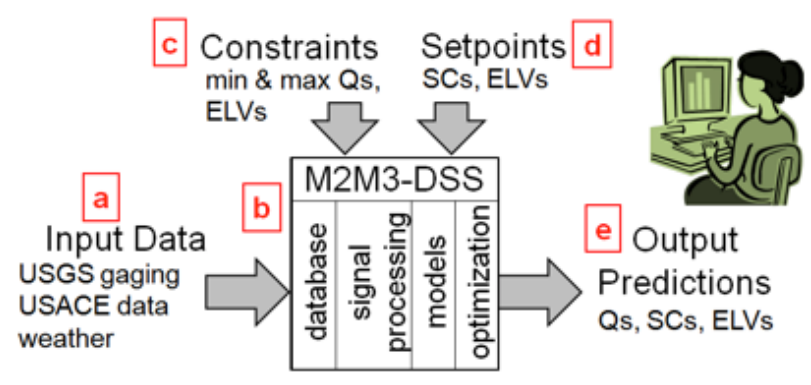

Figure 6. M2M3-DSS deployment schematic

deepening impacts on the estuary's intakes and ecosystems; the experience of the Back River tide gate, whose adverse impacts were not simulated by the pre-construction models; and the demonstrated performance of ANN-based estuary models in several projects.

A DSS similar to the M2M3-DSS could be deployed for daily (or more frequent) use. In Figure 6, current data from the USGS, USACE, and weather stations [a] are input $[\mathrm{b}]$ to the DSS's database and then processed for quality assurance and input to the DSS's near-term weather and tidal forecasts. Constraints [c] on the regulated streamflows, such as the minimums required for scheduled hydropower generation, are entered and stored in the database. Specific conductance and elevation setpoints [d] are similarly entered. The DSS computes "suggested" regulated flows [e] that are optimized for the current and near-term forecasted conditions for use by management personnel.

\section{CONCLUSIONS}

A decision support system like the M2M3-DSS can transform streams of data into the information needed to make informed water management decisions. The simulations described here indicate that a management approach that continuously optimizes water releases might substantially reduce salinity in the Refuge and near municipal intakes while conserving more water in the reservoirs. They also indicate that changes in salinity due to modifications such as the harbor deepening could be quickly quantified, allowing the performance of mitigation factors such as the planned flow-alteration features to be proactively evaluated. The overall approach could be expanded within the Savannah River Basin and possibly applied to other large basins.

\section{LITERATURE CITED}

Allen, J. S., R. T. Carey, L. A. Dickes, E. W. Saltzman, and C. N. Allen, 2010. An economic analysis of low water levels in Hartwell Lake. Strom Thurmond Institute for Government and Public Affairs, Clemson University, Report Submitted to U.S. Army Corps of EngineersSavannah District, $44 \mathrm{p}$.
Conrads, P. A., and E. A Roehl, 1999. Comparing physicsbased and neural network models for simulating salinity, temperature, and dissolved oxygen in a complex, tidally affected river basin. Proc. South Carolina Environmental Conf., Myrtle Beach, March 1999.

Conrads, P. A., E. A. Roehl, and W. P. Martello, 2003. Development of an empirical model of a complex, tidally affected river using artificial neural networks. Proc. National TMDL Science and Policy Specialty Conference, Chicago, November 2003.

Conrads, P. A., E. A. Roehl, R. C. Daamen, and W. M. Kitchens, 2006. Simulation of water levels and salinity in the rivers and tidal marshes in the vicinity of the Savannah National Wildlife Refuge, Coastal South Carolina and Georgia: U.S. Geological Survey Scientific Investigations Report 2006-5187, 134 p.

Conrads, P. A., and E. A. Roehl, 2007. Analysis of salinity intrusion in the Waccamaw River and Atlantic Intracoastal Waterway near Myrtle Beach, South Carolina, 1995-2002: U.S. Geological Survey Scientific Investigations Report 2007-5110, 41 p.

Conrads, P. A., and J. M. Greenfield, 2010. Potential mitigation approach to minimize salinity intrusion in the Lower Savannah River Estuary due to reduced controlled releases from Lake Thurmond. Proc. 4th Federal Interagency Hydrologic Modeling Conf., Las Vegas, NV, June 2010.

Conrads, P. A., E. A. Jr., Roehl, R. C. Daamen, and J. B. Cook, 2013. Simulation of salinity intrusion along the Georgia and South Carolina coasts using climatechange scenarios: U.S. Geological Survey Scientific Investigations Report 2013-5036, 92 p.

Dowla, U., and L. L. Rogers, 1995. Solving Problems in Environmental Engineering and Geosciences with Artificial Neural Networks. MIT Press, p. 60-81.

Grubert, J. P., 1995. Application of neural networks in stratified flow stability analysis. J. Hydraulic Engineering, 121:7:523-532.

Jensen, B. A., 1995 (3rd ed.). Expert Systems-Neural Networks. Instrument Engineers' Handbook, Vol. 2: Process Control (B. G. Liptak, editor). CRC Press, Boca Raton, Fla.

Karunanithi, N., W. J. Grenney, D. Whitley, and K. Bovee, 1994. Neural networks for river flow prediction. $J$. Computing in Civil Engineering, 8:2:201-220.

Maier, H. R, and G. C. Dandy, 1997. Determining inputs for neural network models of multivariate time series, Microcomputers in Civil Engineering, 12:353-368.

Reinert, T. R., 2004. Decline and recovery of striped bass in the Savannah River Estuary: synthesis and re-analysis of historical information and evaluation of restoration potential. Ph.D. Dissertation, University of Georgia, Athens, $134 \mathrm{p}$.

Roehl, E., R. C. Daamen, and P. A. Conrads, 2006. Features of advanced decision support systems for environmental studies, management, and regulation. Proc. 7th Intn'l. Conf. on Hydroinformatics (HIC 2006), Nice, France, September 2006. 
Tetra Tech, 2005, Development of the EFDC hydrodynamic model for the Savannah Harbor. Prepared for the U.S. Army Corps of Engineers - Savannah District, Tetra Tech, Inc. Atlanta, Georgia.

Thirumalaiah, K., and M. C. Deo, 1998. River stage forecasting using artificial neural networks. J. Hydrologic Engineering, 3:1:26-32.

U.S. Army Corps of Engineers, 2014. Final environmental assessment, New operating agreement between U.S. Army Corps of Engineers, Southeastern Power Administration, and Duke Energy Carolinas, LLC, $317 \mathrm{p}$. Welch, Z. C., and W. M. Kitchens, 2006. Predicting freshwater and oligohaline tidal marsh vegetation communities: Florida Cooperative Fish and Wildlife Research Unit, University of Florida, Report Submitted to U.S. Army Corps of Engineers, Solicitation: W9127806-T-0012. 